\title{
Post-spinal cord injury astrocyte-mediated functional recovery in rats after intraspinal injection of the recombinant adenoviral vectors Ad5-VEGF and Ad5-ANG
}

\author{
Tatyana Povysheva, ${ }^{1}$ Maksim Shmarov, PhD, ScD, ${ }^{2}$ Denis Logunov, PhD, ScD, ${ }^{2}$ \\ Boris Naroditsky, PhD, ScD, ${ }^{2}$ llya Shulman, MD, ${ }^{3}$ Sergey Ogurcov, MD, ${ }^{3}$ Pavel Kolesnikov, ${ }^{1}$ \\ Rustem Islamov, MD, PhD, ScD, ${ }^{1}$ and Yuri Chelyshev, MD, PhD, ScD ${ }^{1}$
}

${ }^{1}$ Kazan State Medical University; ${ }^{3}$ Department of Neurosurgery, Republican Clinical Hospital, Kazan; and ${ }^{2}$ Gamaleya Research Institute of Epidemiology and Microbiology, Moscow, Russia

\begin{abstract}
OBJECTIVE The most actively explored therapeutic strategy for overcoming spinal cord injury (SCI) is the delivery of genes encoding molecules that stimulate regeneration. In a mouse model of amyotrophic lateral sclerosis and in preliminary clinical trials in patients with amyotrophic lateral sclerosis, the combined administration of recombinant adenoviral vectors (Ad5-VEGF+Ad5-ANG) encoding the neurotrophic/angiogenic factors vascular endothelial growth factor (VEGF) and angiogenin $(A N G)$ was found to slow the development of neurological deficits. These results suggest that there may be positive effects of this combination of genes in posttraumatic spinal cord regeneration. The objective of the present study was to determine the effects of Ad5-VEGF+Ad5-ANG combination therapy on motor function recovery and reactivity of astrocytes in a rat model of SCl.

METHODS Spinal cord injury was induced in adult Wistar rats by the weight-drop method. Rats $(n=51)$ were divided into 2 groups: the experimental group (Ad5-VEGF+Ad5-ANG) and the control group (Ad5-GFP [green fluorescent protein]). Recovery of motor function was assessed using the Basso, Beattie, and Bresnahan scale. The duration and intensity of infectivity and gene expression from the injected vectors were assessed by immunofluorescent detection of GFP. Reactivity of glial cells was assessed by changes in the number of immunopositive cells expressing glial fibrillary acidic protein (GFAP), S100 $\beta$, aquaporin 4 (AQP4), oligodendrocyte transcription factor 2, and chondroitin sulfate proteoglycan 4. The level of $S 100 \beta$ mRNA expression in the spinal cord was estimated by real-time polymerase chain reaction.
\end{abstract}

RESULTS Partial recovery of motor function was observed 30 days after surgery in both groups. However, Basso, Beattie, and Bresnahan scores were 35.9\% higher in the Ad5-VEGF+Ad5-ANG group compared with the control group. Specific GFP signal was observed at distances of up to $5 \mathrm{~mm}$ in the rostral and caudal directions from the points of injection. A 1.5 to 2.0 -fold increase in the number of $\mathrm{GFAP}^{+}, \mathrm{S}_{100}{ }^{+}$, and $\mathrm{AQP} 4^{+}$cells was observed in the white and gray matter at a distance of up to $5 \mathrm{~mm}$ from the center of the lesion site in the caudal and rostral directions. At 30 days after injury, a 2 -fold increase in $S 100 \beta$ transcripts was observed in the Ad5-VEGF+Ad5-ANG group compared with the control group.

CONCLUSIONS Intraspinal injection of recombinant adenoviral vectors encoding VEGF and ANG stimulates functional recovery after traumatic $\mathrm{SCl}$. The increased number of $\mathrm{S} 100 \beta^{+}$astrocytes induced by this approach may be a beneficial factor for maintaining the survival and function of neurons. Therefore, gene therapy with Ad5-VEGF+Ad5-ANG vectors is an effective therapeutic method for $\mathrm{SCl}$ treatment.

https://thejns.org/doi/abs/10.3171/2016.9.SPINE15959

KEY WORDS spinal cord injury; adenovirus vector; angiogenin; vascular endothelial growth factor; VEGF; astrocyte

\begin{abstract}
ABBREVIATIONS ALS = amyotrophic lateral sclerosis; $A N G=$ angiogenin; $A N G 1=$ angiotensin-1; $A Q P 4=$ aquaporin $4 ;$ BBB = Basso, Beattie, and Bresnahan; CC = central canal; CST = corticospinal tract; DAPI = 4,6'-diamino-2-phenylindole-dihydrochloride; dpi = days post injury; DREZ = dorsal root entry zone; GFAP = glial fibrillary acidic protein; GFP = green fluorescent protein; NG2 = chondroitin sulfate proteoglycan 4; OLIG2 = oligodendrocyte transcription factor 2; PBS = phosphate-buffered saline; $\mathrm{PFU}=$ plaque-forming unit; $\mathrm{RT}-\mathrm{PCR}=$ real-time polymerase chain reaction; $\mathrm{SCl}=$ spinal cord injury; VEGF = vascular endothelial growth factor; $\mathrm{VF}=$ ventral funiculi; $\mathrm{VH}=$ ventral horns
\end{abstract}

SUBMITTED August 13, 2015. ACCEPTED September 23, 2016.

INCLUDE WHEN CITING Published online April 28, 2017; DOI: 10.3171/2016.9.SPINE15959. 
$\mathrm{S}$ PINAL cord injury (SCI) is accompanied by an inflammatory response, excitotoxicity, loss of neurons and glial cells, demyelination, and degeneration of axons, all of which lead to severe functional disorders. The most promising strategy for reversing the effects of SCI is the delivery of therapeutic genes to the site of injury. As a result, the efficacy of direct intraspinal injection of genes encoding molecules that stimulate regeneration, most notably angiogenic and neurotrophic factors, is currently being intensively investigated.

It seems obvious that concomitant delivery of several genes encoding a panel of therapeutic molecules would potentiate therapeutic action through complementary effects on target cells and by enabling the targeting of a wider variety of cell types. Research on the effects of simultaneous delivery of several therapeutic genes for spinal cord trauma is, however, just beginning. Recently, in a rat model of SCI, we showed that delivery of plasmid vectors expressing vascular endothelial growth factor $(V E G F)$ and fibroblast growth factor 2 (FGF2) genes promoted remyelination and the recovery of motor function..$^{28}$ Similarly, the combined delivery of $V E G F$ and angiotensin-1 (ANG1) genes using adeno-associated viral vectors enhanced motor function recovery, supported the preservation of tissue, and stabilized the microcirculatory bed in rats after spinal cord contusion..$^{12}$

VEGF in particular is justifiably considered to be one of the most promising neurotrophic factors for stimulation of neuroregeneration. Through binding and activation of its receptor FLK1, VEGF manifests diverse properties of neurotrophic factors, such as supporting the survival of motor $^{13}$ and sensory ${ }^{30}$ neurons, stimulating neurogenesis, and promoting axon growth ${ }^{21}$ in addition to its well-established roles in inducing angiogenesis. Moreover, in a model of SCI, VEGF was shown to stimulate the proliferation of astrocytes, ${ }^{24}$ neural stem cells, ${ }^{16}$ and Schwann cells. ${ }^{30}$ Injection of an adenoviral vector expressing recombinant $V E G F$ was shown to inhibit neuronal apoptosis and reduce swelling in the area of the damage..$^{23}$ It was further shown that VEGF has a positive effect on the regeneration of corticospinal tract axons.?

Similar to $V E G F$, angiogenin $(A N G)$, a member of the vertebrate-secreted RNAase gene family, is a key factor in stimulating angiogenesis that also exerts neurotrophic effects in the CNS. ${ }^{20}$ ANG injection into the spinal cord posttrauma was shown to increase spinal blood circulation and attenuate the development of a glial scar. ${ }^{4}$ ANG inhibits loss of motor neurons caused by hypoxia and excitotoxicity; however, a mutant form of ANG that is associated with amyotrophic lateral sclerosis (ALS) does not exhibit these effects. ${ }^{27,33}$ In a murine alpha-synuclein model of Parkinson's disease, mice with mutant ANG showed a significant decrease in endogenous $A N G$, and administration of $A N G$ to these animals had a neuroprotective effect..$^{32}$ Together, these data indicate an essential neuroprotective role for $A N G$ in vitro and in vivo, which shows therapeutic promise.

ANG and VEGF are expressed in motor neurons. ANG is secreted by motor neurons and is involved in paracrine mechanisms of regulation that primarily affect astrocytes by influencing their secretory functions. ${ }^{2,29}$ Astrocytes se- crete several proteins with neuroprotective effects on motor neurons, including chemokines, cytokines, proteases and their inhibitors, and proteins involved in the reorganization of the extracellular matrix..$^{29}$ However, it remains to be determined how ANG affects the phenotypic characteristics of astrocytes.

Administration of recombinant human Ad5-type adenoviruses encoding $V E G F$ and $A N G$ (Ad5-VEGF+Ad5ANG) into limb and back skeletal muscles of mutant SOD1 (G93A) transgenic mice, an ALS model, slowed the manifestation of pathological signs, improved motor activity, and increased the life span of these animals. ${ }^{14}$ The same combination of adenoviruses was tested in a 2-year clinical trial and increased the life span of patients with ALS. ${ }^{36}$ Given these findings, we hypothesized that the combination of Ad5-VEGF and Ad5-ANG may be effective in preventing neurodegenerative manifestations of $\mathrm{SCI}$, and we examined this question as described in the present work.

Specifically, the purpose of this study was to evaluate the response of astrocytes in a rat model of SCI to a single injection of a mixture of 2 recombinant adenoviral vectors (Ad5-VEGF and Ad5-ANG) into the area of damage. We first analyzed the efficacy of this gene therapy approach in promoting neuroregeneration after the SCI using standard criteria (e.g., functional parameters such as locomotor activity and infectivity/expression profile). It is important to further assess the effects that vector-based therapy has on specific cell populations. In the present study, we focused on astrocytes because they are the most abundant glial cells and are essential for maintaining homeostasis in the CNS, the dysfunction of which rapidly leads to the development of neurodegeneration.

\section{Methods}

\section{Animal Care and Use}

Experiments were performed using 51 adult male and female Wistar rats (weight 250-300 g; Pushchino Laboratory). Animals were randomly assigned to control $(n=21)$ and experimental $(n=30)$ groups. All animal care and experiments were done under the guidelines of the Kazan State Medical University Animal Care and Use Committee. Animals were housed in standard conditions $(21 \pm$ $3^{\circ} \mathrm{C}, 12$ hours light/dark cycle) with ad libitum access to food and water.

\section{Surgical Procedure}

Rats were deeply anesthetized intraperitoneally with chloral hydrate $(80 \mathrm{mg} / \mathrm{ml}, 0.4 \mathrm{ml}$ per $100 \mathrm{~g}$; Sigma). The surgical area was shaved and disinfected with $70 \%$ ethanol. A skin incision was made parallel to the spine. After obtaining operational access to the spinous processes, 2 parallel longitudinal incisions were made into the bilateral paravertebral muscles. Tendons and muscles were separated from the spinous processes and vertebral arches using a retractor. Bleeding was stopped with a cotton swab moistened with $70 \%$ ethanol at all stages of the operation. A laminectomy was performed at vertebral level T-8. The spine was fixed by placing metal clips at the spinous processes of T-7 and T-9. Weight-drop injury was induced us- 
ing a standardized instrument that releases a weight (10 $\mathrm{g}$, rod diameter $2 \mathrm{~mm}$ ) from a height of $2.5 \mathrm{~mm}$ onto the exposed dura mater of the spinal cord, which inflicts a moderate contusion injury. ${ }^{18}$

\section{Adenovirus Vector}

The recombinant Ad5-VEGF and Ad5-ANG adenoviruses were obtained by the method of homologous recombination in Escherichia coli, as described previously. ${ }^{36}$ Briefly, the human $V E G F$ and $A N G 1$ genes were cloned into a shuttle plasmid vector pShuttle-CMV (Stratagene). These pShuttle-VEGF and pShuttle-Ang plasmids included genomic regions of human adenovirus serotype 5 (Ad5) that are essential for homologous recombination and are expression cassettes for these genes. Homologous recombination was then performed for both pShuttle-VEGF and pShuttleAng with pAdEasy plasmids in $E$. coli strain BJ5183 cells (Stratagene). The resultant pAd5-VEGF and pAd5-Ang constructs respectively contained $V E G F$ or $A N G$ expression cassettes inserted into the E1 genomic deletion. Next, 293 cells were transfected with the pAd5-VEGF or pAd5ANG plasmid after hydrolysis of the PacI restriction enzyme site using Lipofectamin-2000 (Invitrogen).

Expression of VEGF protein was detected 24 hours postinfection by an enzyme immunoassay of the culture medium of 293 cells infected with recombinant adenovirus Ad5-VEGF at a dose of 5 plaque-forming units (PFUs) per cell using the Human VEGF QuantiGlo ELISA Kit (R\&D Systems). Expression of the ANG1 protein was detected in the culture medium of 293 cells infected with the recombinant Ad5-ANG1 adenovirus at a dose of 5 PFUs per cell, 24 hours postinfection. An enzyme immunoassay was performed with the commercial Human Angiogenin Quantikine ELISA Kit (R\&D Systems).

\section{Experimental Groups}

Immediately following SCI, a mixture (1:1) of Ad5VEGF and Ad5-ANG vectors was injected into 2 points $\left(6.4 \times 10^{9}\right.$ PFUs per $8 \mu \mathrm{l}$ saline $)$ at a distance $1-\mathrm{mm}$ rostral and caudal to the center of the injury site and $0.5-\mathrm{mm}$ lateral to the midline using a 5- $\mu$ l Hamilton syringe. The Ad5green fluorescent protein (GFP) adenoviral vector $\left(3.2 \times 10^{6}\right.$ PFUs per $4 \mu \mathrm{l}$ saline) was injected at the above-mentioned points in the control group. After the surgical procedure, rats received daily doses of the antibiotic gentamicin (25 $\mathrm{mg} / \mathrm{kg}$ ) intramuscularly for 7 days postinjury (dpi). After SCI, the urinary function of all rats was disrupted and their bladders were manually expressed twice daily.

\section{Behavioral Analysis}

Locomotor recovery was assessed in an open field using the Basso, Beattie, and Bresnahan (BBB) rating scale. The BBB motor score is widely used to evaluate functional recovery in SCI studies. ${ }^{10,19}$ In rats, BBB motor scores generally improve for the first 4 weeks after injury and then plateau. Animals were adapted to the open field daily for 3 days prior to surgery. The baseline was obtained on the day before SCI. At $7 \mathrm{dpi}$, each rat was evaluated at the same time of day for differences in functional recovery between experimental groups. Locomotion was scored simultaneously by 2 observers, who were blinded to the treatment groups.

\section{Tissue Preparation}

Tissue from rats in the Ad5-VEGF+Ad5-ANG group was harvested after $30 \mathrm{dpi}$. Rats in the Ad5-GFP group were killed for tissue harvest at 2, 4, 7, 14, 21, and 30 dpi. For immunohistochemistry, rats were anesthetized with chloral hydrate and intracardially perfused with $4 \%$ paraformaldehyde (Sigma) in phosphate-buffered saline (PBS; $\mathrm{pH}$ 7.4). Spinal cords $(50-\mathrm{mm}, 2.5-\mathrm{cm}$ rostral and caudal to T-8) were removed and postfixed in $4 \%$ paraformaldehyde at $4^{\circ} \mathrm{C}$ overnight. Sections spanning $5 \mathrm{~mm}$ in the rostral and caudal directions from the center of the injury site were used for immunohistochemistry. Unfixed tissue from the same area was used for real-time polymerase chain reaction (RT-PCR).

\section{Immunofluorescence Methods}

Transverse tissue sections ( $20 \mu \mathrm{m})$ obtained with a cryostat (Microm HM 560, Thermo Scientific) were processed free floating. Sections were washed in PBS with $1 \%$ Triton $\mathrm{X}-100$ (Sigma) 3 times for 5 minutes, and blocked in 5\% normal goat serum for 1 hour at room temperature. For immunofluorescence labeling, sections were treated overnight at $4^{\circ} \mathrm{C}$ with a combination of 3 primary antibodies that label either astrocytes (S100 $\beta$ [1:1200; Dako], glial fibrillary acidic protein [GFAP; 1:200; Santa Cruz Biotechnology], and aquaporin 4 [AQP4; 1:150; Santa Cruz Biotechnology]) or oligodendrocytes (oligodendrocyte transcription factor 2 [OLIG2; 1:150; Santa Cruz Biotechnology] and chondroitin sulfate proteoglycan 4 [NG2; 1:1000; Sigma-Aldrich]). After three 10-minute PBS washes, sections were incubated in a mixture of 3 secondary antibodies: anti-goat Alexa 488 (Invitrogen; 1:150), anti-rabbit Alexa 555 (Invitrogen; 1:200), and anti-mouse Alexa 647 (Invitrogen; 1:200) for 2 hours at room temperature. 4,6'-Diamino-2-phenylindoledihydrochloride (DAPI; $10 \mu \mathrm{g} / \mathrm{ml}$ in PBS; Sigma) was used for visualization of nuclei. Stained sections were embedded in glycerol (GalenoPharm) and observed under an LSM 510-Meta microscope (Carl Zeiss). The numbers of immunopositive cells were blindly quantified in the ventral horns $(\mathrm{VH})$, main corticospinal tract (CST), ventral funiculi (VF), area around the central canal (CC), and dorsal root entry zone (DREZ) in merged images from 10 adjacent optical slices $(512 \times 512-$ pixel resolution, observed area $0.05 \mathrm{~mm}^{2}$; acquisition distance $0.5 \mu \mathrm{m}$ ) (Fig. 1). Only cells with clearly outlined nuclei were considered. ${ }^{5}$ Genuine colocalization was confirmed by viewing the localization of immunopositive cells on orthogonal projections of all 3 channels. The threshold for counting cells as colocalized was a coefficient of colocalization of $\geq 0.5$. Negative controls were obtained using the same protocol, but without the addition of primary or secondary antibodies.

\section{Total RNA Extraction}

Total RNA was extracted from freshly isolated spinal cord segments using Yellow Solve reagents (Silex) according to the manufacturer's protocol. The concentration and purity of RNA were determined spectrophotometrically. Samples of total RNA were stored at $-20^{\circ} \mathrm{C}$ until use. 


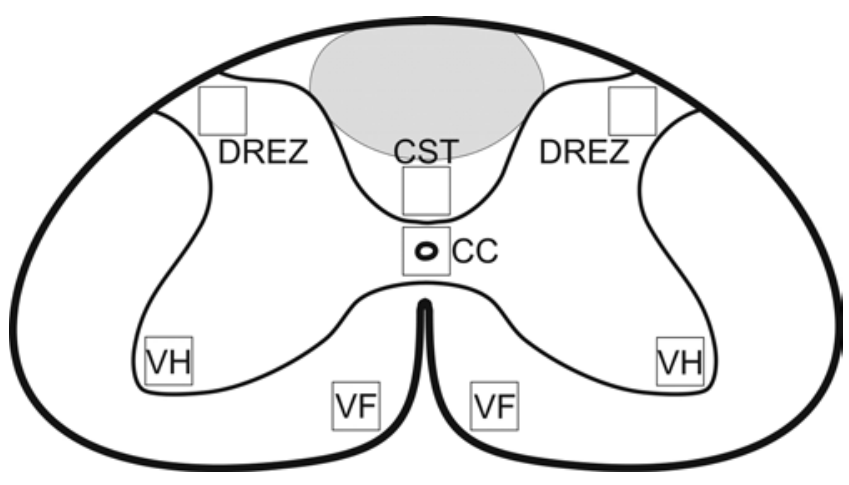

FIG. 1. Morphometry of the anatomical zones analyzed in this study: VF, $\mathrm{VH}$, main CST, DREZ, and CC. The gray field represents the area immediately around the Ad5-VEGF+Ad5-ANG or Ad5-GFP injections.

\section{Reverse Transcription Reaction}

Reverse transcription was achieved using 6-nucleotide random primers (Random6; Syntol) and an Omniscript Reverse Transcription Kit (QIAGEN), according to the manufacturer's instructions. Synthesis of the first strand of cDNA was achieved using 200 U RevertAid Reverse Transcriptase. For cDNA synthesis, an RNA/primer/deoxynucleoside triphosphate mixture containing $100 \mathrm{ng}$ of RNA, $0.5 \mu l$ of Random Hexamer Primers (Litekh), and $8.5 \mu \mathrm{l}$ of $\mathrm{H}_{2} \mathrm{O}$ was denatured at $65^{\circ} \mathrm{C}$ for 5 minutes and then rapidly chilled to $4^{\circ} \mathrm{C}$. cDNA was synthesized using 200 U of RevertAid Reverse Transcriptase, and 20 U of RiboLock RNase inhibitor (Thermo Scientific) in a 20$\mu l$ reaction mixture. After incubation for 10 minutes at $25^{\circ} \mathrm{C}$, the reaction was performed for another 60 minutes at $37^{\circ} \mathrm{C}$.

\section{Quantitative RT-PCR}

Quantitative analysis of mRNA expression levels was performed on an iCycler iQ Real-Time PCR Detection System (Bio-Rad). Each reaction $(15 \mu \mathrm{l})$ contained the PCR Master Mix ( $0.5 \mu l$ of cDNA, 2.5× Reaction Mixture $\mathrm{B}$ for the specific forward and reverse primers, $900 \mathrm{nM}$ of each primer), $300 \mathrm{nM}$ TaqMan fluorescent probe (Synthol), and the target cDNA. A housekeeping gene (18S) was used for normalization purposes. PCR was performed using specific primers obtained from Lytech Solutions for $S 100 \beta$ and $18 S$ (Table 1).

Amplification parameters were set according to the manufacturer's protocol: preheating at $95^{\circ} \mathrm{C}$ for 3 minutes followed by 45 cycles of $95^{\circ} \mathrm{C}$ for 30 seconds and $60^{\circ} \mathrm{C}$ for 50 seconds, including plate read. Expression results for target genes were obtained from 2 independent experiments containing 3 samples each. For relative quantitation, cDNA from the sciatic nerve was used to construct a standard curve and determine the level of gene expression. The gene expression level in intact control spinal cord (nontransduced control) was considered to be $100 \%$.

\section{Statistical Analysis}

Data are expressed as the mean \pm standard error of the mean (SEM). To determine statistical significance, we used a Student t-test distribution or a 1-way ANOVA with
TABLE 1. Nucleotide sequences of primers and probes used for quantitative analysis by RT-PCR

\begin{tabular}{ll}
\hline \multicolumn{1}{c}{ Transcript Name } & \multicolumn{1}{c}{ Sequence of Primers \& Probes } \\
\hline 18S-TM-F & gccgctagaggtgaaattcttg \\
\hline 18S-TM-R & cattcttggcaaatgctttcg \\
\hline 18S-TM probe* & [HEX]accgcgcaagacggaccag[BHQ2] \\
\hline rS100B-TM49F & gagagagggtgacaagcaca \\
\hline rS100B-TM110R & caccacttcctgctctttga \\
\hline rS100B-TM probe* & [FAM]cgagctctctctcacttcctggaggaa[BHQ1] \\
\hline * TaqMan probe contains a 5' FAM (5-Carboxyfluorescein), HEX fluorescent \\
label, and 3' BHQ1 or BHQ2 quenchers.
\end{tabular}

Tukey's test. A p value of 0.05 was considered statistically significant. All analyses were performed in a blinded manner with respect to the treatment group. Data were analyzed using Origin 7.0 SR0 software (OriginLab).

\section{Results}

\section{BBB Locomotor Scores}

Motor activity of the hind limbs was practically absent in the experimental and control groups at 6 dpi. The first signs of recovery of motor function were observed at 6-12 $\mathrm{dpi}$, at which time increased GFP marker expression was observed in the control group (Ad5-GFP) (Fig. 2). The highest rate of motor activity was registered in the experimental group, Ad5-VEGF+Ad5-ANG. The average score on the BBB test at 15-30 dpi was 9.6 points for the Ad5VEGF+Ad5-ANG group and 6.3 points for the Ad5-GFP group. The average score on the BBB test at 7-30 dpi was $8.00 \pm 1.42$ in the Ad5-VEGF+Ad5-ANG group versus $6.17 \pm 1.13$ in the Ad5-GFP group.

During the initial recovery period, setting of the foot

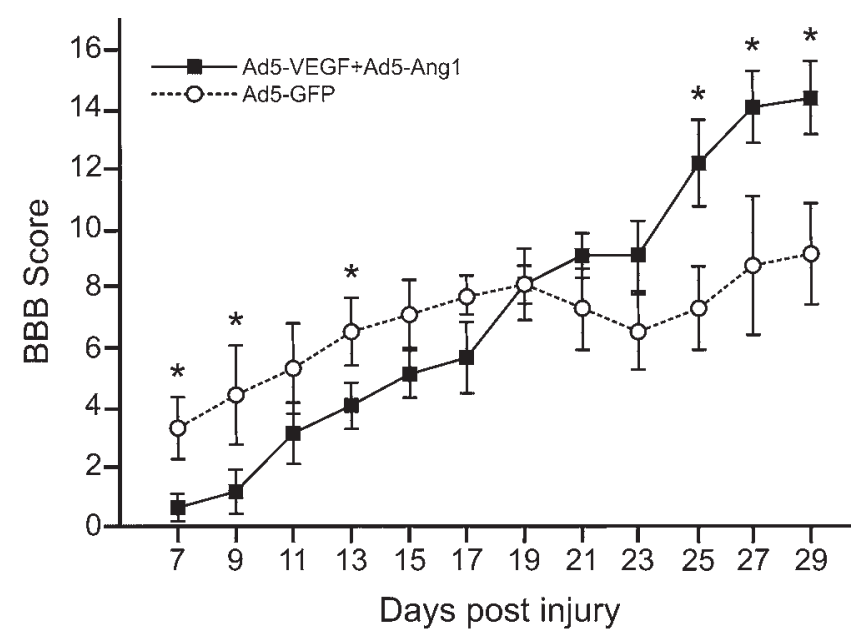

FIG. 2. Time course of BBB score changes following SCl. At $7 \mathrm{dpi}$, BBB scores decreased markedly to $0.6 \pm 0.4$ in the Ad5-VEGF+Ad5ANG and $3.1 \pm 0.4$ in the Ad5-GFP groups. By 4 weeks after SCI, BBB scores gradually increased in both groups. The final BBB score in the Ad5-VEGF+Ad5-ANG group was $14.3 \pm 0.8$ whereas it was $8.4 \pm 0.8$ in the Ad5-GFP group. The asterisks indicate statistically significant differences between the Ad5-VEGF+Ad5-ANG and Ad5-GFP groups $(p<$ 0.05, 1-way ANOVA). 
plantar and the ability to support body weight was observed in the Ad5-GFP group. In the Ad5-VEGF+Ad5ANG group, weak and isolated weak, but clearly defined, movements of 1 or 2 joints of the hind limbs were also observed. The periods of 9-17 dpi for the Ad5-VEGF+Ad5ANG group and 6-19 dpi for the Ad5-GFP group could be defined as the phase in which improvement in stability occurred. We observed declines in BBB scores until Day 23 dpi in the Ad5-GFP group. However, significant improvement in motor activity was observed at 24-29 dpi in the Ad5-VEGF+Ad5-ANG group. Moreover, these rats were capable of making constant plantar steps with retention of body weight and coordinated movements of the front and hind limbs. Together these data indicate greater functional improvement in the Ad5-VEGF+Ad5-ANG group by the end of the observation period.

\section{Expression of GFP in Ad5-GFP-Infected Cells}

The expression levels and time course of the adenoviral vector were studied by analyzing GFP expression in the region of damage (level T-8). We found that GFP was specifically expressed in a range spanning 5-mm rostral and caudal to the point of injection. Fluorescence signal was first observed in the early stages after injury (2-4 dpi), peaked at 7-14 dpi, and gradually faded by 30 dpi (Fig. 3). GFP-labeled cells were observed in gray and white matter. In addition, cells ectopically penetrated into the cavity. Fluorescent cells were predominantly expressed in white matter at $1 \mathrm{dpi}$. At $4 \mathrm{dpi}$, GFP-labeled cells formed clusters with intense fluorescence in the ventral posterior cords and were particularly prominent in areas adjacent
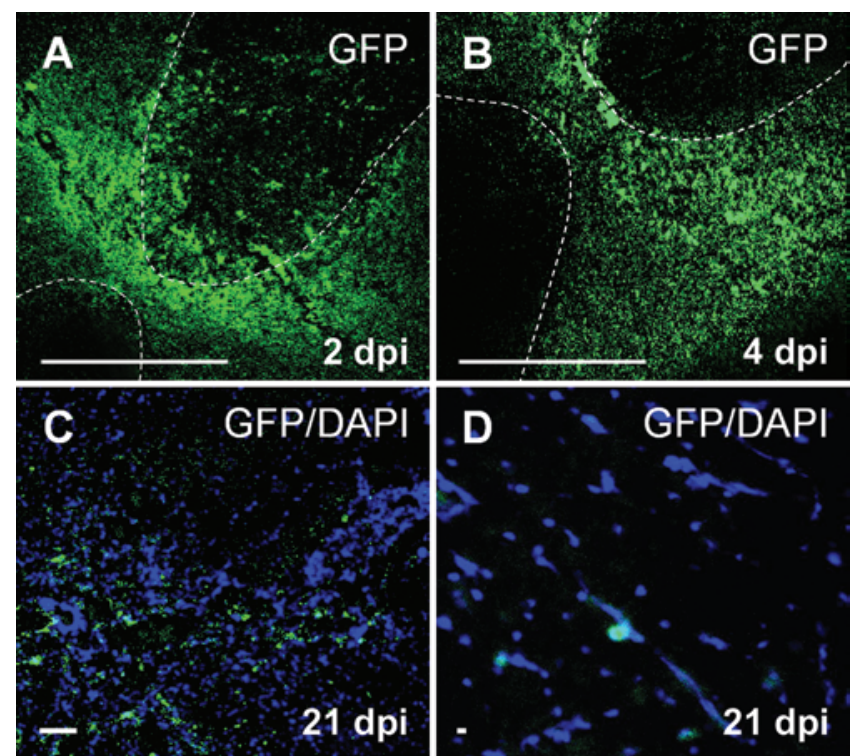

FIG. 3. GFP expression within and near the injection site after Ad5-GFP delivery. Intense GFP expression was seen at 2 dpi (A). GFP-labeled cells formed clusters with intense fluorescence in the dorsal gray matter at $4 \mathrm{dpi}(\mathrm{B})$. The area containing $\mathrm{GFP}^{+}$cells narrowed significantly at 21 dpi ( $C$ and D). Nuclei were counterstained with DAPI in the 21-dpi images $(C$ and $D)$. The dashed line delineates the border between the gray and white matter. All images were obtained by confocal microscopy. Scale bars $=50 \mu \mathrm{m}$ in $A$ and $B, 20 \mu \mathrm{m}$ in $C$, and $5 \mu \mathrm{m}$ in D. Figure is available in color online only. to the dorsal gray matter. The largest volume of tissue expressing GFP was observed $4 \mathrm{dpi}$. The area containing $\mathrm{GFP}^{+}$cells was significantly smaller at 14-21 dpi (Fig. 3). At this time, GFP fluorescence was mainly detected in a compact cluster of cells located mainly in the ventral posterior cords between the border with gray matter.

\section{Reactivity of Astrocytes}

Cells expressing specific markers of astroglia were found in the white matter of the center of the spinal cord lesion in all groups at $30 \mathrm{dpi}$. Significant increases in the number of astrocytes were also observed in the gray matter at a distance of $5 \mathrm{~mm}$ in the rostral and caudal directions from the center of the lesion. The number and distribution of $\mathrm{GFAP}^{+}, \mathrm{S}_{100} \beta^{+}$, and $\mathrm{AQP}^{+}$astrocytes in the white and gray matter were significantly different between the experimental and control groups (Figs. 4 and 5). We counted cells in sections as far as $5 \mathrm{~mm}$ from the center of the lesion in the rostro-caudal axis. We observed a decrease in the number of $\mathrm{GFAP}^{+}, \mathrm{S}_{100} \beta^{+}$, and $\mathrm{AQP} 4^{+}$cells of 2.0-, 1.5-, and 1.9-fold, respectively, in all areas of the white and gray matter analyzed in the Ad5-GFP group compared with the Ad5-VEGF+Ad5-ANG group. We observed differences in the size of the soma and processes of $\mathrm{GFAP}^{+}$and $\mathrm{S} 100 \beta^{+}$cells in the white and gray matter in all groups. The size of the perikaryon in astrocytes expressing the proteins S100 $\beta$ and GFAP was greater in the Ad5VEGF+Ad5-ANG group than in the Ad5-GFP group in all areas. In addition to differences throughout the whole white matter, we observed differences in the number of astrocytes in specific regions of the spinal cord.

\section{GFAP Expression}

Counts of $\mathrm{GFAP}^{+}$cells revealed significant differences between the Ad5-VEGF+Ad5-ANG group and the Ad5-GFP group in all areas of the white and gray matter analyzed, other than the CST. Specifically, the numbers of $\mathrm{GFAP}^{+}$cells in the Ad5-VEGF+Ad5-ANG group relative to the control group in each region were as follows: DREZ $(23.75 \pm 1.89$ [Ad5-VEGF+Ad5-ANG] vs $8.00 \pm$ 2.65 [Ad5-GFP]), CC (29.01 \pm 1.91 [Ad5-VEGF+Ad5ANG] vs $17.00 \pm 2.82$ [Ad5-GFP] $), \mathrm{VF}(10.04 \pm 2.38$ [Ad5-VEGF+Ad5-ANG] vs $4.41 \pm 1.05$ [Ad5-GFP]), and VH $(19.10 \pm 1.00$ [Ad5-VEGF+Ad5-ANG] vs $10.00 \pm 1.42$ [Ad5-GFP]). The largest difference was observed in the DREZ, where the number of $\mathrm{GFAP}^{+}$cells was $>3$ times higher in the Ad5-VEGF+Ad5-ANG group than in the Ad5-GFP group.

\section{S100 $\beta$ Expression}

The number of $\mathrm{S} 100 \beta^{+}$cells was increased in areas of the white and gray matter in the center of the injury site in the Ad5-VEGF+Ad5-ANG group. However, the only significant increase was observed in $\mathrm{VH}$, where the difference was approximately 2-fold (16.04 \pm 0.71 [Ad5$\mathrm{VEGF}+\mathrm{Ad} 5-\mathrm{ANG}]$ vs $8.12 \pm 1.06$ [Ad5-GFP]).

\section{AQP4 Expression}

Counts of $\mathrm{AQP}^{+}$cells revealed significant increases between the Ad5-VEGF+Ad5-ANG group and the Ad5- 
GFP group in the CST $(8.00 \pm 2.03$ [Ad5-VEGF+Ad5ANG] vs $4.02 \pm 1.04$ [Ad5-GFP]), DREZ (17.01 \pm 1.98 [Ad5-VEGF+Ad5-ANG] vs $8.00 \pm 1.96$ [Ad5-GFP]), and $\mathrm{VH}(12.00 \pm 1.00[\mathrm{Ad} 5-\mathrm{VEGF}+\mathrm{Ad} 5-\mathrm{ANG}]$ vs $5.08 \pm 0.94$ [Ad5-GFP]).

\section{Reactivity of Oligodendrocytes \\ OLIG2 Expression}

Quantification of the number of OLIG2+ cells (Fig. 6) revealed significant increases between the Ad5-VEGF+Ad5ANG group and the Ad5-GFP group in the CC (38.14 \pm 1.98 [Ad5-VEGF+Ad5-ANG] vs $30.05 \pm 2.08$ [Ad5-GFP]) and CST $(31.05 \pm 1.85$ [Ad5-VEGF+Ad5-ANG] vs 24.12 \pm 1.64 [Ad5-GFP]).

\section{NG2 Expression}

Counts of $\mathrm{NG}^{+}$cells revealed significant increases in the $\mathrm{CC}$ in the $\mathrm{Ad} 5-\mathrm{VEGF}+\mathrm{Ad} 5-\mathrm{ANG}$ group relative to the Ad5-GFP group (20.16 \pm 2.22 [Ad5-VEGF+Ad5ANG] vs $15.64 \pm 3.42$ [Ad5-GFP]) and DREZ (29.04 \pm 2.98 [Ad5-VEGF+Ad5-ANG] vs $21.15 \pm 1.18$ [Ad5-GFP]), and significant decreases between the same groups in the $\mathrm{VH}(8.12 \pm 1.20[\mathrm{Ad} 5-\mathrm{VEGF}+\mathrm{Ad} 5-\mathrm{ANG}]$ vs $14.16 \pm 3.28$ [Ad5-GFP]).

\section{OLIG2/NG2 Coexpression}

The number of $\mathrm{OLIG} 2^{+} / \mathrm{NG}^{2}{ }^{+}$cells was decreased in areas of the white and gray matter in the center of the injury site in the Ad5-VEGF+Ad5-ANG group, as well as in the $\mathrm{CC}(1.28 \pm 0.53[\mathrm{Ad} 5-\mathrm{VEGF}+\mathrm{Ad} 5-\mathrm{ANG}]$ vs 4.12 \pm 0.86 [Ad5-GFP]), CST (2.61 \pm 1.53 [Ad5-VEGF+Ad5ANG] vs $6.13 \pm 1.08$ [Ad5-GFP] $)$, and DREZ $(2.75 \pm 0.96$ [Ad5-VEGF+Ad5-ANG] vs $5.00 \pm 1.32$ [Ad5-GFP]).

\section{mRNA Expression of $\mathbf{S} 100 \beta$}

mRNA was extracted from the center of the lesion to quantify $S 100 \beta$ gene expression levels 30 days after the administration of Ad5-VEGF+Ad5-ANG or Ad5-GFP (Fig. 7). RT-PCR revealed a significant reduction in $S 100 \beta$ mRNA expression in the Ad5-VEGF+Ad5-ANG group (18-fold) and the Ad5-GFP group (34-fold) compared with the intact spinal cord. The differences in $S 100 \beta$ mRNA levels between the Ad5-VEGF+Ad5-ANG group and the Ad5-GFP group were also significant, indicating that expression was higher in the Ad5-VEGF+Ad5-ANG group than in the Ad5-GFP group.

\section{Discussion}

In this study, we determined that vector-based expression of VEGF and ANG after SCI was effective in improving recovery from SCI, probably through effects on the astrocyte population. Specifically, combined treatment with Ad5-VEGF and Ad5-ANG led to improved locomotor recovery. Similarly, we have previously shown improvement in motor function at 30 dpi after administering an adenovirus driving recombinant glial-derived neurotrophic factor expression immediately after injury in the same experimental model of spinal cord contusion.
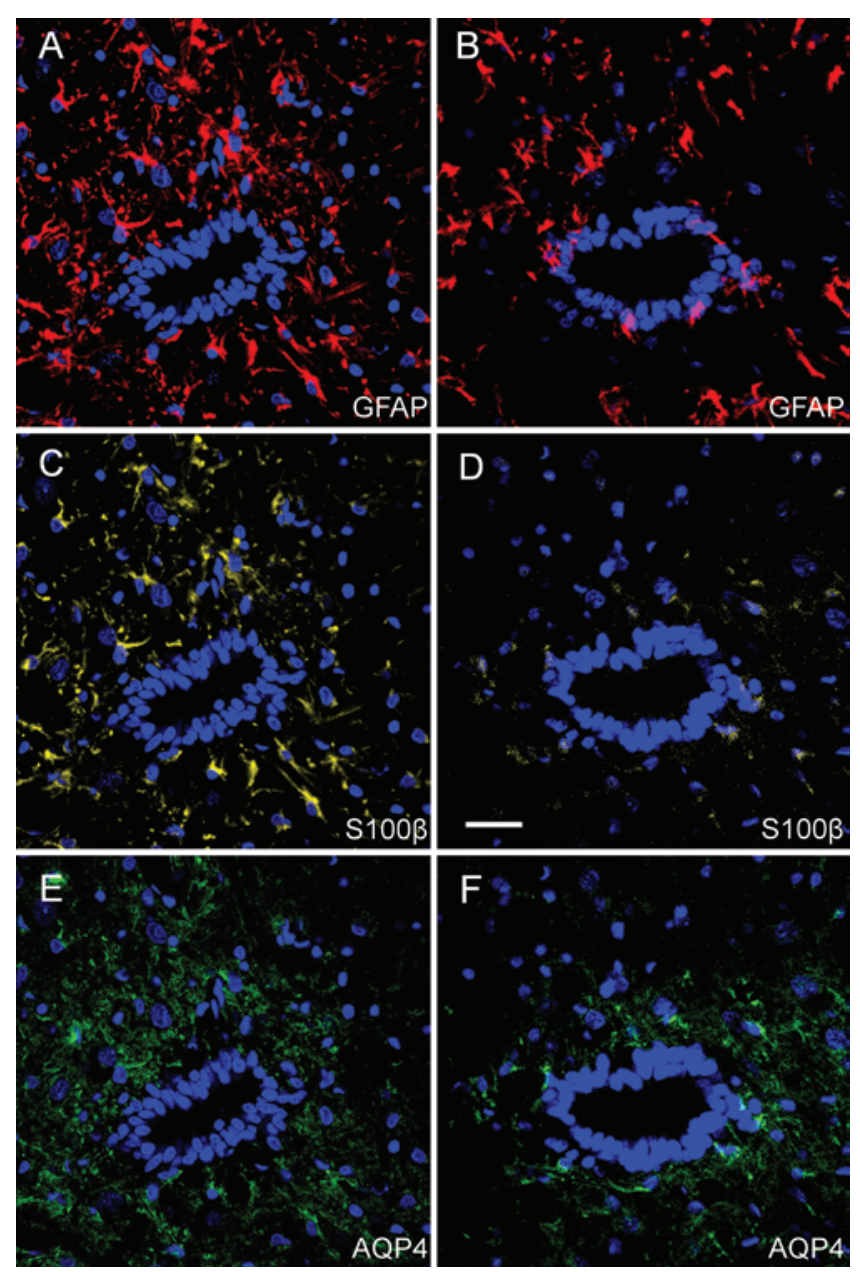

FIG. 4. Immunohistochemical staining of sections from the center of the lesion site with anti-GFAP (red), anti-S100 $\beta$ (yellow), and antiAQP4 (green) antibodies to label astrocytes in the CC 30 days after administration of Ad5-VEGF+Ad5-ANG (A, C, and E) and Ad5-GFP $(B, D$, and $F)$. There was increased GFAP immunoreactivity in the Ad5VEGF+Ad5-ANG group compared with the Ad5-GFP group. The size of the perikaryon of astrocytes expressing $S 100 \beta$ and GFAP was larger in the Ad5-VEGF+Ad5-ANG group than in the Ad5-GFP group. Nuclei were counterstained with DAPI. All images were obtained by confocal microscopy. Scale bar $=20 \mu \mathrm{m}$. Figure is available in color online only.

\section{Vector Targeting and Expression}

For vector-expressed therapeutic genes to enable recovery of functions lost or impaired after SCI, the virus must be effectively transduced in the area of injury and tolerated by targeted cells. Herein, we observed significant and stable expression of GFP after Ad5-GFP injection even at the time of injury, rather than after the peak of the cytostatic action of proinflammatory cytokines and cellular immune responses (12-72 hours). This indicates a sufficiently high capacity of the administered recombinant adenoviral vector Ad5 to transduce cells in the area of injury. Moreover, viral transduction was relatively widespread. Indeed, the detection of transduced cells throughout a radius of $5 \mathrm{~mm}$ from the site of administration in the rostro-caudal direction may indicate either substantial diffusion of the virus in the intercellular space, or pronounced migratory potential of cells that were transduced 

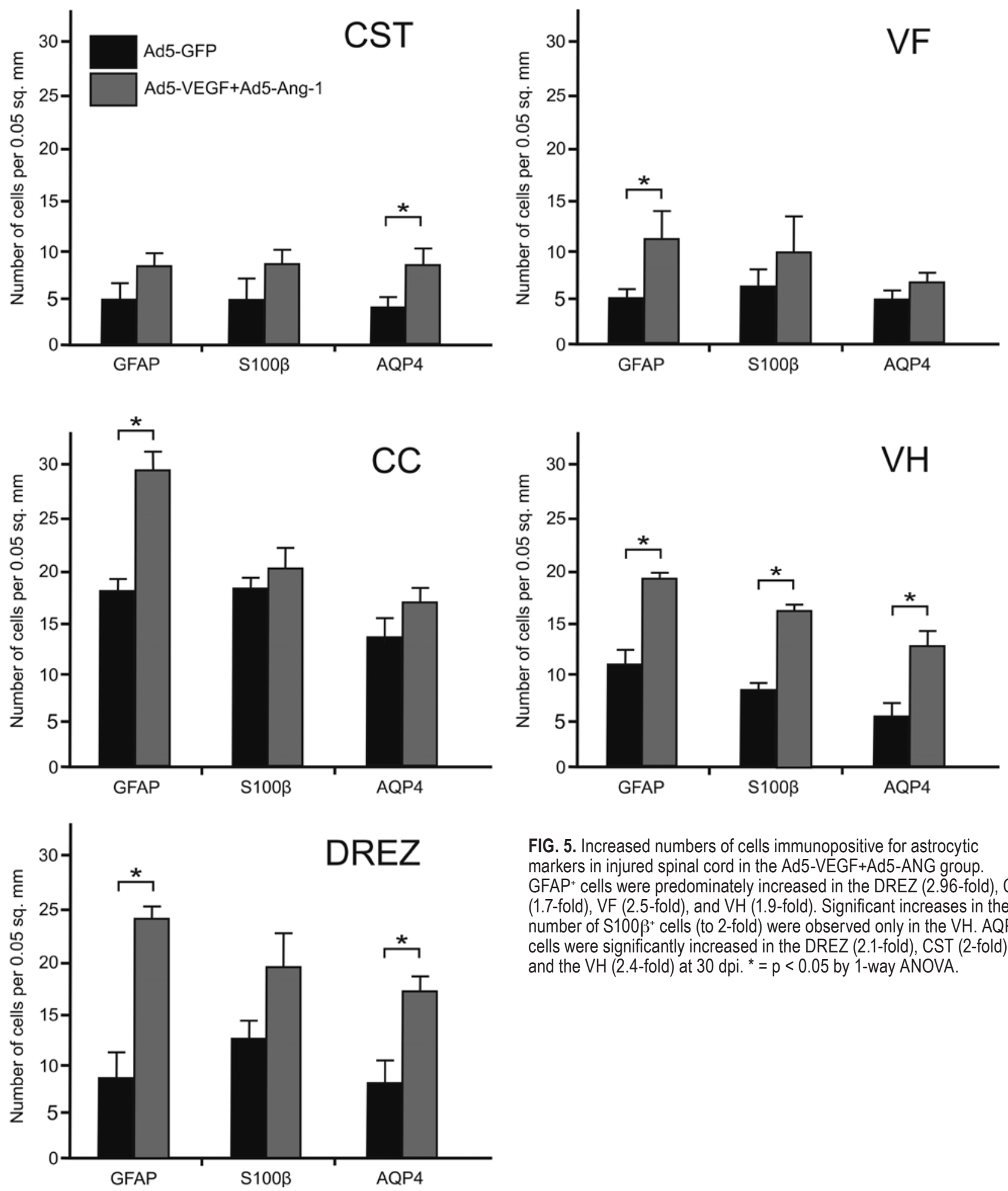

FIG. 5. Increased numbers of cells immunopositive for astrocytic markers in injured spinal cord in the Ad5-VEGF+Ad5-ANG group. $\mathrm{GFAP}^{+}$cells were predominately increased in the DREZ (2.96-fold), CC (1.7-fold), VF (2.5-fold), and VH (1.9-fold). Significant increases in the number of $S 100 \beta^{+}$cells (to 2 -fold) were observed only in the VH. AQP4 ${ }^{+}$ cells were significantly increased in the DREZ (2.1-fold), CST (2-fold), and the $\mathrm{VH}(2.4$-fold $)$ at $30 \mathrm{dpi}^{*}{ }^{*}=p<0.05$ by 1 -way ANOVA.

in the vicinity of the injection points. In either case, our approach was able to therapeutically target genes to a substantial area of the affected spinal cord.

These results are consistent with those of Wang et al., ${ }^{35}$ who observed Ad-GFP-transduced cells in the spinal cord at a distance of 4 and $6 \mathrm{~mm}$ in the rostral and caudal directions from the point of injection, respectively. Our obser- vation of weak GFP fluorescence at 3-6 dpi and stronger fluorescence at 14 dpi also corresponds to data reported by Wang et al. ${ }^{35}$ The observation of GFP-expressing cells in the area of injury as long as 30 days after infection indicates that it may be possible to provide sufficiently stable expression of the transgene that is necessary to achieve the objectives of direct gene therapy for neurorestoration. ${ }^{10}$ 

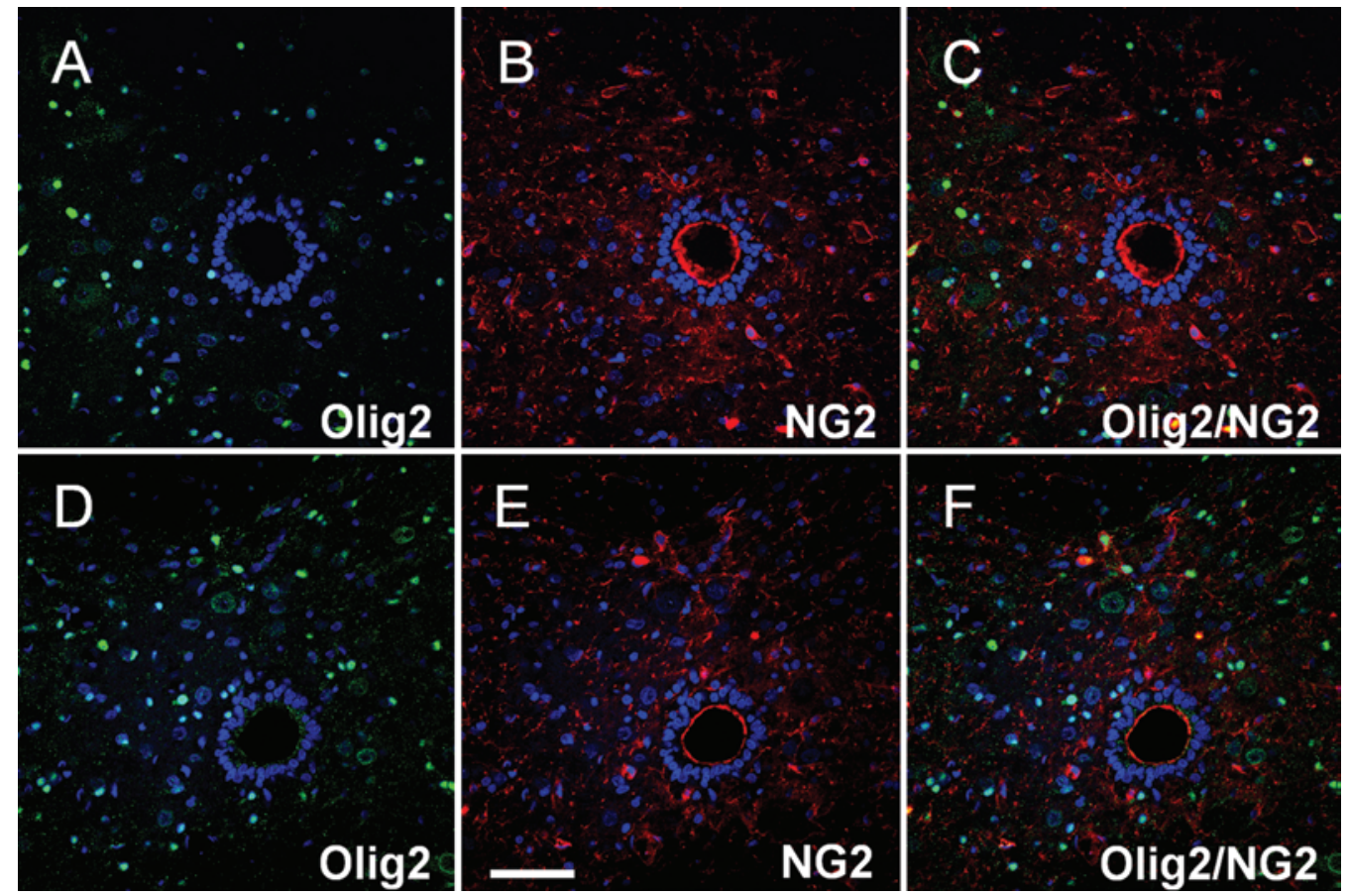

FIG. 6. Confocal immunofluorescence showing the association of the oligodendrocyte precursor marker NG2 with the pan-oligodendrocyte marker OLIG2 in imaging fields showing the area around the CC 30 days after administration of Ad5-VEGF+Ad5-ANG $(A-C)$ or Ad5-GFP (D-F). The images indicate that there was increased OLIG2 (green) and NG2 (red) immunoreactivity in the Ad5-VEGF+Ad5-ANG group ( $A$ and B) compared with the Ad5-GFP group ( $D$ and E). Note that NG2 fibers and oligodendrocyte cell bodies (OLIG2 ${ }^{+}$cells) are colocalized (C and F). Nuclei were counterstained with DAPI. Scale bar $=20 \mu \mathrm{m}$. Figure is available in color online only.

\section{Dosage Effects}

The importance of selecting the proper dose of virus to promote regeneration was highlighted by several observations in this study. In terms of the dynamics of the recovery of motor function, we observed a biphasic pattern: during the first $14 \mathrm{dpi}, \mathrm{BBB}$ scores were higher in the control group (Ad-GFP), whereas from 14 to $30 \mathrm{dpi}$, BBB scores were higher in the Ad5-VEGF+Ad5-ANG group. This may be due to the fact that the total dose of virus in the Ad5-VEGF+Ad5-ANG group was 2-fold higher than it was in the control Ad-GFP group, which perhaps led to an increase in the number of proinflammatory cytokines and inflammatory reactivity in the Ad5-VEGF+Ad5-ANG group during early stages. Thus, increased inflammation in the Ad5-VEGF+Ad5-ANG group may have initially impaired the recovery process. However, in the subsequent phase (from 14 to $30 \mathrm{dpi}$ ), there was an attenuation of inflammation, allowing the therapeutic effects of the transgenes to take hold and promote improved recovery of motor function. Based on these data, it can be assumed that a reduction in the dose of the Ad5-VEGF+Ad5-ANG adenoviral vectors would potentially constrain the inflammatory response in the early stages after injury and provide even greater improvements in motor function recovery.

\section{Roles of Astrocytes in VEGF- and ANG-Based Gene Therapy}

At the cellular level, our data demonstrate that VEGF and $A N G$ gene delivery increases the number of astrocytes in the lesion area. Increases in the number of astrocytes in the Ad5-VEGF+Ad5-ANG group may enhance the production of neurotrophic factors and induce remodeling of the lesion environment to allow axon growth. The most pronounced increase in the number of $\mathrm{GFAP}^{+}$astrocytes was found in the DREZ (2.5- to 3-fold), which may be explained by the proximity of this area to the site of injection. However, an increase of approximately the same size was observed in VF, which is an area remote from the site of injection. Therefore, another explanation for the difference in changes in the number of $\mathrm{GFAP}^{+}$astrocytes is that $\mathrm{GFAP}^{+}$astrocyte populations are heterogeneous across regions, and these phenotypically distinct subpopulations may react differently to damage and therapy.

Recovery of motor function improved with the introduction of Ad5-VEGF+Ad5-ANG. The number of GFAP ${ }^{+}$ cells increased in the majority of areas of both the white and gray matter of the spinal cord. This may be explained by the broad roles that astrocytes play in injury responses and in providing support to neurons, both proximal to the soma and in distal projections. After injury, mature astrocytes respond rapidly to local environmental cues by undergoing hypertrophy, proliferating, and migrating to the edge of the lesion site. ${ }^{3}$ The astrocyte response to injury is necessary for successful homeostasis and tissue repair. The protective functions of astrocytes involve close metabolic coupling with neurons, the modulation of neuronal excitability, production of neurotrophic factors, glutamate clearance, antioxidant defense mechanisms, and mainte- 


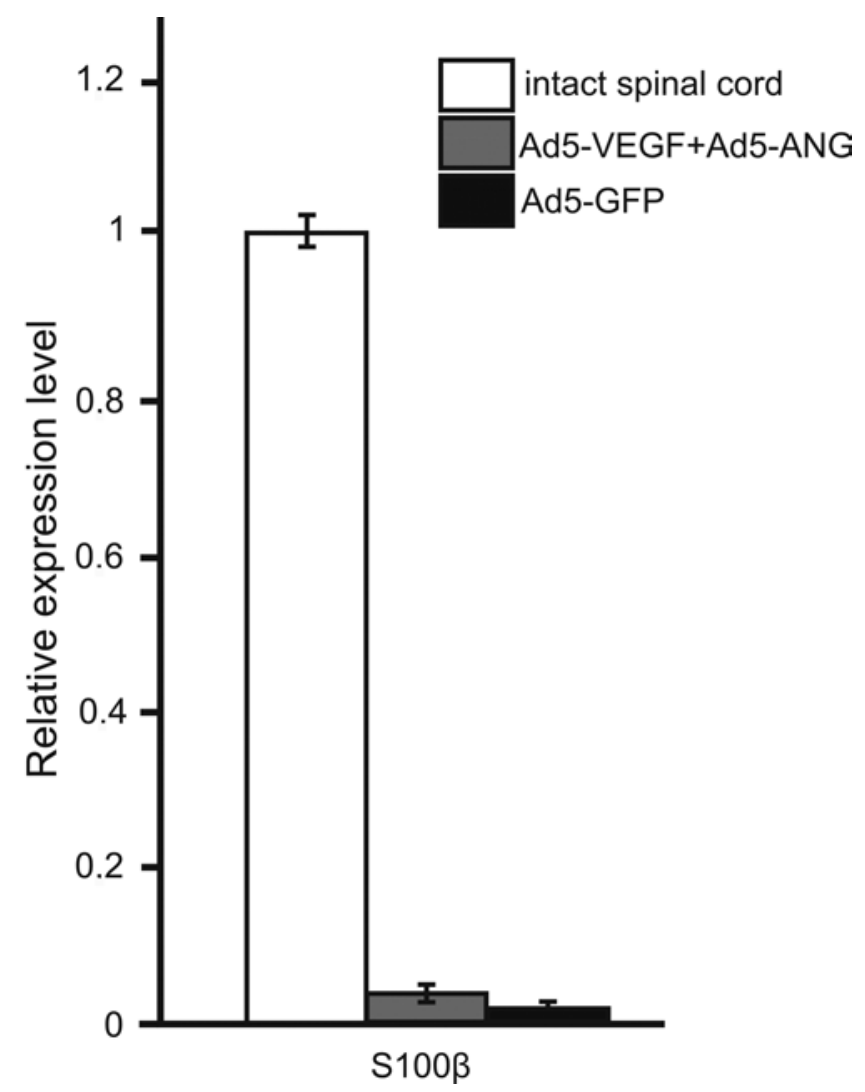

FIG. 7. Quantitative RT-PCR of S100 $\beta$ gene expression. RT-PCR assays at $30 \mathrm{dpi}$ revealed a significant reduction in $S 100 \beta$ mRNA expression normalized to $S 18$ in the Ad5-VEGF+Ad5-ANG group (18-fold) and the Ad5-GFP group (34-fold) compared with the intact spinal cord. By 1 -way ANOVA, $p$ values were $<0.01$ between all groups (intact spinal cord, Ad5-VEGF+Ad5-ANG, and Ad5-GFP).

nance of the extracellular ionic environment, as has been reviewed in detail elsewhere. ${ }^{1,11,25}$ In addition, reactive astrocytes produce extracellular matrix molecules that provide a substrate supportive to axon growth. ${ }^{6}$ On the other hand, reactive astrocytes form a dense scar and produce chondroitin sulfate proteoglycans, molecules that are inhibitory to axon growth. ${ }^{7,17}$ Understanding the balance between the protective and inhibitory functions of astrocytes is important to devising strategies that will promote beneficial astrocytic repair functions following injury, while limiting the harmful effects of reactive astrocytes. With respect to our data, it is unclear to what extent the increase in the number of $\mathrm{GFAP}^{+}$astrocytes correlates with the recovery of motor function; in other words, is an improvement of motor function due to-or despite-astrogliosis?

At 30 dpi, Ad5-VEGF+Ad5-ANG gene therapy led to an increase in the number of $\mathrm{AQP}^{+}$astrocytes of approximately 2-fold in both the white and gray matter of the spinal cord. AQP4 expression changes, including timedependent decreases and increases, are observed in spinal cord trauma. ${ }^{22}$ Increased expression of AQP4 in the chronic postinjury phase may be related to regulation of water homeostasis, because a protective astrocytic function is AQP4-mediated water influx, which accompanies increased uptake of chloride and potassium ions.
Another potentially important molecule for protective astrocytic functions that we assessed in this study is S100 $\beta$, a $\mathrm{Ca}^{2+}$-binding protein produced mainly by astrocytes that exerts autocrine and paracrine effects on neurons and glia, while also playing an important role in cellular metabolism, cytoskeletal reorganization, cell proliferation, and differentiation. ${ }^{26}$ Moreover, S100 $\beta$ supports the survival of motor neurons and is considered to be a neurotrophic factor in the spinal cord..$^{15}$ These data are consistent with the established notions that $\mathrm{S} 100 \beta$ family members are involved in the regulation of protein phosphorylation, enzymatic activity, and the expression of cytoskeletal proteins and transcription factors. ${ }^{8}$ In addition, members of the $S 100 \beta$ family can be released into the extracellular space, where they influence the viability of neurons and the proliferation and differentiation of astrocytes. S100 $\beta$ protein at low concentrations in the extracellular space has a trophic effect on neurons and reduces microglial reactivity through actions mediated by receptors for advanced glycation end products. ${ }^{31}$

Normally, astrocytic expression of $\mathrm{S} 100 \beta$ protein in the lesion area is considerably reduced compared with the intact spinal cord at $30 \mathrm{dpi}$. This decrease in $\mathrm{S} 100 \beta$ may be due to posttraumatic death of S100 $\beta^{+}$astrocytes. In our study, we observed an increase in the population of S100 $\beta^{+}$astrocytes in the spinal cord of rats in the Ad5VEGF+Ad5-ANG group that was most pronounced in VH, where $\mathrm{S} 100 \beta$ primarily localized around the perikarya of motor neurons. The findings of improved locomotor function and increased expression of S100 $\beta$ after combined administration of Ad5-VEGF and Ad5-ANG point to the effectiveness of this therapy. We should note that a previous report demonstrated a 2 -fold increase in the $S 100 \beta$ protein level at the site of injury at $1 \mathrm{dpi}^{34}$ that, according to the authors, may have been due to the involvement of this protein in the inflammatory response during development of secondary damage or extravasation of damaged blood vessels. However, in our study, there were no apparent signs of acute inflammation at $30 \mathrm{dpi}$, indicating that increased $\mathrm{S} 100 \beta$ protein expression can be mainly attributed to expression in $\mathrm{S} 100 \beta^{+}$astrocytes after blood-brain barrier integrity has been restored.

In our study, we showed a correlation between improvement of locomotor recovery after SCI in rats and the number of astrocytes, which was increased after intraspinal injection of 2 recombinant adenoviral vectors (Ad5-VEGF and Ad5-ANG). It is well established that Ad5 can transduce many different types of mammalian eukaryotic cells in vivo. It is also well known that astrocytes play a role in spinal motor neuron plasticity. Based on these 2 considerations, we suggest that, in our study, Ad5-VEGF and Ad5ANG may have transduced both glial and neuronal cells. This suggests that expression of recombinant VEGF and ANG may have transduced neurons and glia and that this respectively resulted in neuronal autocrine and astrocytic paracrine regulation of target cell activity. Thus, VEGFand ANG-mediated activity of astrocytes results in functional recovery in rats after SCI.

One of the most severe consequences of SCI is the destruction of myelin fibers. Remyelination is an important factor for restoration of the neural connections in the spi- 
nal cord after injury. We therefore assessed the population of myelin-forming cells (OLIG2-immunopositive oligodendrocytes) and their precursors (NG2-immunopositive cells) after viral-mediated expression of VEGF and ANG, and observed increased numbers of oligodendrocytes and their precursors in treated rats. We therefore speculate that VEGF and ANG may promote remyelination of nerve fibers affected by SCI and thereby stimulate recovery of the spinal cord.

\section{Conclusions}

Delivery of the therapeutic genes $V E G F$ and $A N G$ using an adenoviral vector improved functional recovery after traumatic SCI. Immunofluorescent analysis of the spinal cord showed that the numbers of $\mathrm{GFAP}^{+}, \mathrm{S} 100 \beta^{+}$, and $\mathrm{AQP}^{+}$astrocytes, and of $\mathrm{OLIG}^{+}$and $\mathrm{NG}^{+}$oligodendrocyte-lineage cells, were significantly increased in the spinal cord with treatment. Thus, the positive effect of Ad5-VEGF+Ad5-ANG transduction on recovery of locomotor function may be due to the action of glial cells on motor neurons. Taken together, our results suggest that gene therapy with Ad5-VEGF+Ad5-ANG may be an effective approach for treating SCI in clinical practice.

\section{Acknowledgments}

We thank Y. O. Mukhamedshina and E. E. Cherenkova (Openlab Gene and Cell Technologies, Kazan [Volga Region] Federal University, Kazan, Russia) for their assistance in some experiments. The study was supported by grant no. 16-15-00010 from the Russian Science Foundation.

\section{References}

1. Allaman I, Bélanger M, Magistretti PJ: Astrocyte-neuron metabolic relationships: for better and for worse. Trends Neurosci 34:76-87, 2011

2. Aparicio-Erriu IM, Prehn JH: Molecular mechanisms in amyotrophic lateral sclerosis: the role of angiogenin, a secreted RNase. Front Neurosci 6:167, 2012

3. Buffo A, Rite I, Tripathi P, Lepier A, Colak D, Horn AP, et al: Origin and progeny of reactive gliosis: a source of multipotent cells in the injured brain. Proc Natl Acad Sci U S A 105:3581-3586, 2008

4. Chamoux M, Dehouck MP, Fruchart JC, Spik G, Montreuil J, Cecchelli R: Characterization of angiogenin receptors on bovine brain capillary endothelial cells. Biochem Biophys Res Commun 176:833-839, 1991

5. Chelyshev YA, Muhamedshina YO, Povysheva TV, Shaymardanova GF, Rizvanov AA, Nigmetzyanova MV, et al: Characterization of spinal cord glial cells in a model of hindlimb unloading in mice. Neuroscience 280:328-339, 2014

6. Costa S, Planchenault T, Charriere-Bertrand C, Mouchel Y, Fages C, Juliano S, et al: Astroglial permissivity for neuritic outgrowth in neuron-astrocyte cocultures depends on regulation of laminin bioavailability. Glia 37:105-113, 2002

7. Cregg JM, DePaul MA, Filous AR, Lang BT, Tran A, Silver J: Functional regeneration beyond the glial scar. Exp Neurol 253:197-207, 2014

8. Donato R, Cannon BR, Sorci G, Riuzzi F, Hsu K, Weber DJ, et al: Functions of S100 proteins. Curr Mol Med 13:24-57, 2013

9. Facchiano F, Fernandez E, Mancarella S, Maira G, Miscusi M, D'Arcangelo D, et al: Promotion of regeneration of corticospinal tract axons in rats with recombinant vascular en- dothelial growth factor alone and combined with adenovirus coding for this factor. J Neurosurg 97:161-168, 2002

10. Figley SA, Liu Y, Karadimas SK, Satkunendrarajah K, Fettes P, Spratt SK, et al: Delayed administration of a bioengineered zinc-finger VEGF-A gene therapy is neuroprotective and attenuates allodynia following traumatic spinal cord injury. PLoS One 9:e96137, 2014

11. Hamby ME, Sofroniew MV: Reactive astrocytes as therapeutic targets for CNS disorders. Neurotherapeutics 7:494-506, 2010

12. Herrera JJ, Sundberg LM, Zentilin L, Giacca M, Narayana PA: Sustained expression of vascular endothelial growth factor and angiopoietin-1 improves blood-spinal cord barrier integrity and functional recovery after spinal cord injury. J Neurotrauma 27:2067-2076, 2010

13. Islamov RR, Chintalgattu V, Pak ES, Katwa LC, Murashov AK: Induction of VEGF and its Flt-1 receptor after sciatic nerve crush injury. Neuroreport 15:2117-2121, 2004

14. Ismailov ShM, Barykova IuA, Shmarov MM, Tarantul VZ, Barskov IV, Kucherianu VG, et al: [Experimental approach to the gene therapy of motor neuron disease with the use of genes hypoxia-inducible factors.] Genetika 50:591-601, 2014 (Russian)

15. Iwasaki Y, Shiojima T, Kinoshita M: S100 $\beta$ prevents the death of motor neurons in newborn rats after sciatic nerve section. J Neurol Sci 151:7-12, 1997

16. Jin H, Liu ML, Kim HA, Lee M, An S, Oh J, et al: Role of the oxygen-dependent degradation domain in a hypoxiainducible gene expression system in vascular endothelial growth factor gene therapy. Spine (Phila Pa 1976) 34:E952E958, 2009

17. Kawano H, Kimura-Kuroda J, Komuta Y, Yoshioka N, Li HP, Kawamura K, et al: Role of the lesion scar in the response to damage and repair of the central nervous system. Cell Tissue Res 349:169-180, 2012

18. Lebedev SV, Timofeyev SV, Zharkov AV, Schipilov VG, Chelyshev JA, Masgutova GA, et al: Exercise tests and BBB method for evaluation of motor disorders in rats after contusion spinal injury. Bull Exp Biol Med 146:489-494, 2008

19. Liu Y, Figley S, Spratt SK, Lee G, Ando D, Surosky R, et al: An engineered transcription factor which activates VEGF-A enhances recovery after spinal cord injury. Neurobiol Dis 37:384-393, 2010

20. Mac Millan M, Stauffer ES: Traumatic instability in the previously fused cervical spine. J Spinal Disord 4:449-454, 1991

21. Mackenzie F, Ruhrberg C: Diverse roles for VEGF-A in the nervous system. Development 139:1371-1380, 2012

22. Nesic O, Guest JD, Zivadinovic D, Narayana PA, Herrera JJ, Grill RJ, et al: Aquaporins in spinal cord injury: the Janus face of aquaporin 4. Neuroscience 168:1019-1035, 2010

23. Qiang H, Zhang C, Shi Z, Ling M: [Neuroprotective effects of recombinant adeno-associated virus expressing vascular endothelial growth factor on rat traumatic spinal cord injury and its mechanism.] Zhongguo Xiu Fu Chong Jian Wai Ke Za Zhi 26:724-730, 2012 (Chinese)

24. Rosenstein JM, Mani N, Silverman WF, Krum JM: Patterns of brain angiogenesis after vascular endothelial growth factor administration in vitro and in vivo. Proc Natl Acad Sci U S A 95:7086-7091, 1998

25. Rossi D, Volterra A: Astrocytic dysfunction: insights on the role in neurodegeneration. Brain Res Bull 80:224-232, 2009

26. Rothermundt M, Peters M, Prehn JHM, Arolt V: S100B in brain damage and neurodegeneration. Microsc Res Tech 60:614-632, 2003

27. Sebastià J, Kieran D, Breen B, King MA, Netteland DF, Joyce $\mathrm{D}$, et al: Angiogenin protects motoneurons against hypoxic injury. Cell Death Differ 16:1238-1247, 2009

28. Shaymardanova GF, Mukhamedshina YO, Salafutdinov II, 
Rizvanov AA, Chelyshev YA: Usage of plasmid vector carrying VEGF and FGF2 genes after spinal cord injury in rats. Bull Exp Biol Med 154:544-547, 2013

29. Skorupa A, Urbach S, Vigy O, King MA, Chaumont-Dubel S, Prehn JH, et al: Angiogenin induces modifications in the astrocyte secretome: relevance to amyotrophic lateral sclerosis. J Proteomics 91:274-285, 2013

30. Sondell M, Sundler F, Kanje M: Vascular endothelial growth factor is a neurotrophic factor which stimulates axonal outgrowth through the flk-1 receptor. Eur J Neurosci 12:42434254,2000

31. Sorci G, Riuzzi F, Arcuri C, Tubaro C, Bianchi R, Giambanco I, et al: S100B protein in tissue development, repair and regeneration. World J Biol Chem 4:1-12, 2013

32. Steidinger TU, Standaert DG, Yacoubian TA: A neuroprotective role for angiogenin in models of Parkinson's disease. J Neurochem 116:334-341, 2011

33. Subramanian V, Feng Y: A new role for angiogenin in neurite growth and pathfinding: implications for amyotrophic lateral sclerosis. Hum Mol Genet 16:1445-1453, 2007

34. Tsai MC, Shen LF, Kuo HS, Cheng H, Chak KF: Involvement of acidic fibroblast growth factor in spinal cord injury repair processes revealed by a proteomics approach. Mol Cell Proteomics 7:1668-1687, 2008

35. Wang X, Smith GM, Xu XM: Preferential and bidirectional labeling of the rubrospinal tract with adenovirus-GFP for monitoring normal and injured axons. J Neurotrauma 28:635-647, 2011
36. Zavalishin IA, Bochkov NP, Suslina ZA, Zakharova MN, Tarantul VZ, Naroditskiy BS, et al: Gene therapy of amyotrophic lateral sclerosis. Bull Exp Biol Med 145:483-486, 2008

\section{Disclosures}

The authors report no conflict of interest concerning the materials or methods used in this study or the findings specified in this paper.

\section{Author Contributions}

Conception and design: Povysheva, Islamov, Chelyshev. Acquisition of data: Povysheva, Chelyshev. Analysis and interpretation of data: Povysheva, Chelyshev. Drafting the article: Povysheva, Shmarov, Islamov, Chelyshev. Critically revising the article: all authors. Reviewed submitted version of manuscript: all authors. Approved the final version of the manuscript on behalf of all authors: Povysheva. Statistical analysis: Povysheva. Administrative/technical/material support: all authors. Study supervision: Povysheva, Shmarov, Islamov, Chelyshev.

\section{Correspondence}

Tatyana Vyacheslavovna Povysheva, Kazan State Medical University, 49 Butlerova Str., Kazan 420009, Russia. email: t.povysheva@gmail.com. 